\title{
CORPOS QUE CONTAM HISTÓRIAS: PERFORMANCE E IDENTIDADE DE "CONTADORES DE CAUSOS" DA FRONTEIRA
}

\author{
Luciana Hartmann ${ }^{170}$ (UFSM)
}

Após diversos anos pesquisando as performances narrativas de contadores de causos/cuentos da região da fronteira entre Argentina, Brasil e Uruguai, passei a trabalhar com a noção de performance sob duas perspectivas complementares: como espetáculo e como forma de organização e transmissão da experiência. Neste artigo procuro refletir sobre a relação entre espetacularidade, experiência e significado a partir de referências teóricas e de dados empíricos, obtidos em pesquisas de campo realizadas desde 1997. Inicialmente situo teoricamente meu trabalho, apresentando de que forma compreendo e utilizo o conceito de performance. Num segundo momento enfoco uma narrativa com características "espetaculares", visando depreender desta tanto as estratégias de performance utilizadas pelos membros desta comunidade narrativa quanto suas características estéticas. Num terceiro e último momento a história de vida de uma narradora da fronteira será considerada sob o pressuposto de que, ao observar os eventos narrados (o conteúdo) em conjunto com o evento narrativo (a performance), se possa compreender as experiências que deles emergem.

Quando iniciei minha análise sobre os eventos narrativos observados durante a pesquisa de campo, adotei a proposição de Kapchan (1995), que relaciona a performance às práticas estéticas que envolvem padrões de comportamento, maneiras de falar e maneiras de se comportar corporalmente. Segundo a autora, as repetições destas formas específicas de agir situam os atores sociais no tempo e no espaço, estruturando identidades individuais e de grupo. Ao longo de meu trabalho, no entanto, passei a considerar que se poderia (ou deveria) acrescentar a esta definição algumas outras características da performance, como fazer uso da linguagem poética, do corpo ser o veículo que dá forma ao que se quer comunicar e de que todo ato de performance é reflexivo, cria uma experiência ao mesmo tempo que reflete sobre ela. Em relação à noção de linguagem poética, inspiro-me naquilo que Jakobson (1974) atribui à linguagem verbal, ampliando-o ao nível da linguagem corporal: na poética estão envolvidas seleções e combinações não usuais de elementos. Além disso, a função poética é a única dentre as funções da linguagem que trata da própria mensagem, ou seja, é auto-referenciada, logo, propicia reflexão sobre os próprios processos constitutivos da linguagem. Ao conferir a devida importância da corporalidade nesta conceituação, presto tributo, entre tantos outros autores, a Mauss (1974) e Zumthor (2000). E ao assumir a reflexividade inerente a todo ato performático estou bebendo na fonte inevitável que nos oferece - a todos que trabalham com performance - Victor Turner (1981, 1992).

${ }^{170}$ Professora do Departamento de Artes Cênicas 
Considero a performance, assim, não apenas como mais um objeto de pesquisa, mas como "o" objeto de pesquisa privilegiado para dar conta do universo multifacetado, fragmentado, processual e dialógico da cultura. Este conceito, entretanto, se salienta por possuir usos e conotações bastante diferenciadas (ver, entre outros, Bauman, 1977; 1989; Langdon, 1999; Schechner, 1988, 1992; Schieffelin, 1996, 1998; Singer, 1972; Turner, 1981, 1992; Zumthor, 2000)

Como mencionei acima, em minha pesquisa trabalho com o conceito sob duas perspectivas. Por um lado, identifico as narrativas pessoais com um tipo de performance cuja ênfase não estava no desempenho vocal e corporal do contador, mas no conteúdo da narrativa, ou seja, no "evento narrado". Esta forma de manifestação, que chamei inicialmente de performance como desempenho, possui como principal característica o foco na experiência do narrador, que utiliza a performance como forma de organizar esta experiência (para si mesmo) e transmiti-la à comunidade. A idéia de experiência, no entanto, tem superado, em minhas análises, a noção de desempenho, e é por este motivo que procuro neste momento reaproximá-la do conceito de performance. Por outro lado, em grande parte das performances dos causos/cuentos da fronteira observo que há um maior envolvimento do contador no próprio ato de narrar. Ao priorizar o "evento narrativo", o contador empenha-se em tornar sua performance mais elaborada esteticamente e para isto recorre a uma série de estratégias, como o uso de linguagem poética (Jakobson, 1974), de dispositivos narrativos tradicionais (Dégh, 1995), etc. Com início e fim bem definidos e com a presença de uma audiência caracterizada como tal, esta forma de expressão possui nitidamente contornos espetaculares. Para fins desta comunicação, trabalharei com a primeira forma, a partir de um exemplo etnográfico de uma performance como desempenho.

O evento narrativo aqui apresentado ocorreu no "lado" uruguaio e pode ser considerados, dentro de minha perspectiva analítica, da mesma forma que os eventos ocorridos no "lado" argentino e no "lado" brasileiro (que constam de minha tese de doutorado - Hartmann, 2004). Todos são, nesta perspectiva, "da fronteira" ${ }^{\prime 171}$.

\section{Dona Nair - performance como transmissão da experiência}

Embora o objetivo inicial de minha pesquisa fosse observar e conhecer performances narrativas públicas, mais ligadas à idéia de espetáculo, acabei sentido a necessidade de fazer um redirecionamento para as narrativas pessoais, acompanhando uma tendência surgida durante a realização da própria pesquisa de campo. Ao sentar-me junto a um narrador previamente indicado por pessoas da sua comunidade eu, antes de tudo, explicava-lhe os objetivos de minha estada ali. As narrativas, entretanto, não surgiam sem estímulo e a minha sugestão,

\footnotetext{
${ }^{171}$ Venho realizando pesquisa de campo na região da fronteira entre Argentina, Brasil e Uruguai desde 1998, numa faixa que avança em torno de $100 \mathrm{Km}$ nos limites políticos de cada um dos países.
} 
"para começo de conversa", era que o narrador me contasse um pouco sobre sua vida. Eu procurava deixar que as histórias tomassem seu próprio rumo, ainda que muitas vezes mencionasse aqueles episódios ou referências que me haviam sido informadas no momento da indicação daquele contador. É evidente que este método de trabalho possivelmente embutisse aquilo que Bertaux (1997) denomina de "filtro" que muitos dos narradores eram indicados justamente em função de episódios notáveis de suas histórias de vida e de sua reconhecida habilidade para contálos, e não necessariamente por seu desempenho na narração histórias tradicionais (os "causos" ou cuentos). E conquanto as narrativas pessoais se prestassem grandemente aos meus propósitos de reconhecimento e análise das relações sociais na fronteira, devo observar que as histórias de domínio público, que não faziam parte da experiência direta dos contadores, eventualmente também afloravam em meio às suas histórias de vida. Utilizando estratégias como "eu nunca vi, mas o meu pai uma vez me contou...", os contadores poderiam incluir "causos" conhecidos, como da "mulher de branco", por exemplo, como parte de suas narrativas pessoais.

Desta forma, ao longo de minha pesquisa de campo as histórias de vida dos narradores eram contadas em eventos que envolviam ou não a presença dos causos/cuentos. O conhecimento das trajetórias pessoais e das histórias tradicionais, adquirido a partir da etnografia, proporcionou, assim, um acesso direto - já que transmitido pelos próprios habitantes da região - às principais características e valores que constituem a cultura local. Neste trabalho procuro analisar alguns aspectos que conformam esta "cultura da fronteira" a partir de um episódio da história de vida de uma contadora da região.

Quando contou esta narrativa, Dona Nair, de 69 anos, moradora de Cerro Pelado/UY, surpreendeu à mim e à Verônica (professora do Liceu Rural e minha "guia" na ocasião), que apesar de conhecê-la há bastante tempo, desconhecia este episódio de sua vida. Dona Nair é viúva, está aposentada e mora com uma filha numa das viviendas (casas) construídas em sistema cooperativo pela população local. Ela me foi indicada por ser antiga moradora da região, ou seja, a idade e a experiência a autorizam a contar. Embora seja dona de casa, esta contadora foi esposa de um capataz e acompanhou-o em seu trabalho em estâncias, habitando sempre no meio rural, tanto no lado brasileiro como no lado uruguaio da fronteira, daí o seu "trânsito" pelos países e pelos idiomas.

A performance verbal de Dona Nair, devido à esta vivência, é caracterizada especialmente pela alternância dos idiomas espanhol e português. A contadora também utiliza diversas estratégias narrativas, como o alongamento de determinadas sílabas em palavras que são, desta maneira, especialmente enfatizadas. Estas estratégias serão demonstradas através de

\footnotetext{
${ }^{172}$ Para este autor, as experiências narradas passam pelo filtro de quem escuta, no caso, o pesquisador: «dans le récit de vie ethonosociologique, forme orale et plus spontanée, et surtout forme dialogique, le sujet est d'emblée invité par le chercheur à considérer ses expériences passées à travers un filtre.» (Bertaux, 1997: 34).
} 
dispositivos textuais que procuram aproximar a transcrição das narrativas da forma como são expressas na oralidade ${ }^{173}$. São eles:

- mudanças de linha representam a separação de sentenças/pausas de respiração;

- letras maiúsculas indicam pronúncias em volume mais alto;

- repetição de vogais indicam sílabas alongadas;

- grafia propositalmente incorreta de algumas palavras (como são pronunciadas na forma oral);

- negrito indica ênfase dada pelo contador à determinada palavra;

- itálico representa palavras em espanhol, mescladas à linguagem corrente brasileira (em português);

- parênteses com reticências indicam cortes - edição da fala na transcrição;

- as chaves são utilizadas para a inclusão de observações da pesquisadora.

Em relação à performance corporal, Dona Nair permaneceu durante todo o tempo sentada e sua atuação se desenvolveu basicamente através do uso de gestual lento e horizontalizado - o que corrobora com minhas observações anteriores - realizado em momentos específicos da narrativa, e de expressões faciais que buscavam denotar o sentimento evocado naquele momento da história.

A narrativa deste trágico episódio da vida de Dona Nair surgiu no primeiro encontro que tive com ela, depois de quase uma hora de conversa, encadeada na sequiência da história sobre um dos homens mais ricos da região, um brasileiro, que começara sua fortuna fazendo negócios em um armazém localizado na linha de fronteira. $\mathrm{O}$ fato de que este homem morava com uma tia foi o mote para a nova narrativa:

DN - Essa tia do Marcelino... Carolina se chamava a véia. E tu sabe que essa véia escreveu uma... nós dissemo uma décima ${ }^{174}$, de uma irmã minha que se matou? O noivo matou ela com quinze anos, ela era a mais véia, e despôs [palavra que mescla os dois idiomas] se matou [a contadora inicia com um resumo da história, despertando o interesse da audiência].

Eu - Uma irmã sua?

DN - Sim. A minha irmã mais véia que tinha um namorado e... e despôs que ele tava com vinte e dois anos ele entrou em amores [linguagem poética] com ela, e ela tinha quinze. E os meus pais a princípio não

\footnotetext{
${ }^{173}$ Inspiro-me sobretudo nos trabalhos de Tedlock $(1983,1990)$. O autor propõe que as principais indicações da performance vocal sejam feitas através de sinais gráficos - como os que procuro utilizar - e que os comentários do pesquisador (interpretações) sejam feitas não "entre" as passagens ou seqüências narrativas mas "com" cada uma delas.

${ }^{174}$ Denominação local para uma forma poética, que pode ser observada na sequiência da fala de Dona Nair.
} 
queriam deixaaar porque ela era mиy jovem, mas como eles não queriam se deixar eles resolveram a ceder que eles se casassem, não é? [relação com a audiência (função fática ${ }^{175}$ )] Pero os pais de criação dele disseram que recém que ele ia pagar a criação, que ele tava inventando de casar [contexto] E empezaran a privar, privar... foi quando ele inventou de se matar. Pero que prá se matar ele tinha que matar ela, entonce foi o que ele fez. Lá um certo dia [cronologia dos fatos] ele veio nas casas ${ }^{176} \mathrm{de}$ manhã, que não era costume dele viiir, despôs se foi prá casa deeele, despôs de tarde vieeeram e saííram a pescaar, com nós tooodos. E volteeemo...

\section{Eu - E a senhora tinha que idade nessa época?}

DN - Eu tinha sete anos. E voltemo prás casa (...) E aí a Mama mandou a minha irmã, a outra que seguia a mais véia, a ir prender as luz prá ir prá dentro de casa. E foi dando tezinho [chazinho] prá Selanira, que é essa que mora no Brasil, que tinha seis meses, seis meses tinha. $\mathrm{E}$ tava dando tezinho ansim e olhou prá guria - porque elas tinham muito cuidado com as filhas, né [contexto]- olhou prá pequenininha, que tava tomando té, que não fosse se afogar, e quando levantou a cabeça diz que ele arrumou a silla [cadeira] bem prá perto da silla dela e então conversou bem no ouvido dela, e não era costume [moral local]. E ela [sua mãe] disse que não quis falar nada porque aí ficava prá falar com ela despôs, reclamar prá ela, não é? [relação com a audiência] Que não era costume, porque ficava feio. Essa gente antiga era muy delicada [contexto]. E deixou. E ela agachou a cabeça prá reparar a gurizinha e quando levantou a cabeça, relampeou o revólver. E ele deu um tiro nela e dali já saiu com o revólver no ouvido ansim, prá trás, prá trás, até que se pegou um tiro. Ficou três bala. Se matou ali em seguidinha.

\section{Eu - E a senhora onde é que tava nessa hora?}

DN - Tava aliii. Nós tava todas com a minha mãe [testemunho], só não tava o meu pai com os outros ermão [palavra que mescla os dois idiomas], pero as guria mulher tavam todas ali. E a minha mãe tentou agarrar ele, a perseguir ele, pero caiu com a minha irmã nos braços, com essa de seis meses, porque foi-lhe as pernas, não é? Uma perseguiçããão... [elaboração semelhante à narrativa de ficção] Foi que ficou as três bala. Pero se matou, ele queria se matar ali junto com ela. Disso foi que sacaran a décima essa, que eu te disse que a tia do Marcelino sacou. (...) Ela botou ansim:

\section{Norberto foi pedir licença}

\footnotetext{
${ }^{175}$ As funções da linguagem (entre elas a função fática e a função poética), são descritas e analisadas por Jakobson (1974).

176 "Las casas" refere-se à casa, moradia. Segundo Don Heber, de Minas de Corrales/UY, a expressão é utilizada no plural porque é comum, na campanha, sobretudo nas estâncias, a existência de várias construções, como a casa do capataz, cozinha e refeitório dos peões, dormitórios dos empregados, galpões de diferentes tamanhos, etc. Ao fazer uso desta expressão Dona Nair indica que o evento narrado ocorreu no meio rural, denotando, como foi apontado no início deste artigo, a familiaridade da população fronteiriça com a "ruralidade".
} 
dos seus pais para casar

Como não quiseram dar,

Norberto pensou em suicidar-se

Norberto vivia pensando

no que devia fazer

Que para ele se suicidar,

Clara devia morrer

Norberto vivia pensando, pensava noite e dia, e no rosto dele se notava

o quanto Norberto sofria.

Era um domingo formoso, regulando as oito horas Quando Norberto assassinou a sua querida Clara

Ela era linda e formosa, toda de branco vestida Parecia uma rosa naquele instante colhida

Chora mãe carinhosa, que a tua Flora já morreu Foi mais um botão de rosa que desabrochou no céu

Eu também lamento muito dessa mãe muito sentida Que dessa mesma morte eu perdi uma filha querida ${ }^{177}$

Estas duas diferentes formas de expressão oral, inseridas numa mesma narrativa, permitem observar como uma experiência da "vida real" se transforma em prosa e verso. As palavras que traduzem o evento narrado são de tal forma organizadas, lapidadas, que lhe conferem uma feição mágica, característica do universo ficcional: "ela era linda e formosa, toda de branco vestida.." A tragicidade do evento, aliada à feição de testemunho do relato e à

\footnotetext{
${ }^{177}$ Dona Nair ainda conclui com uma observação sobre o seu processo de memorização, relacionado à constante repetição da história, tanto pela comunidade quanto por ela própria: "Eu não posso me lembrar... Ainda me faltam uns pedaços, que uns pedaços eu não me lembro. O que passa é que eu me esqueço. Eu nem era prá me lembrar, eu tinha sete anos! Pero despôs, como eu sempre vivia repetindo, viviam repetindo, e eu me lembrei porque eu era muиuito vivaracha e tudo que cantavam, tudo que falavam, eu em seguida aprendia."
} 
memória e habilidade de Dona Nair como narradora, fazem com que ambos, evento e narrativa, resistam ao tempo, o que, no exemplo dado, significa mais de sessenta anos.

Neste caso, a tradição, como aponta Dégh (1995), não se encontra necessariamente na história (evento narrado), mas na forma pela qual a performance (que consta do evento narrativo) é organizada: escolha do tema violento pela narradora; introdução da narrativa através de um pequeno resumo, visando atrair a atenção da audiência; uso de expressões poéticas características da região ("entrou em amores"); apelo à audiência nas finalizações de algumas sentenças ("não é?"); alongamento de palavras, enfatizando determinados fatos e construindo a idéia de temporalidade da narrativa - usualmente lenta na região; movimentação corporal centrada no uso das mãos e das expressões faciais (como já foi mencionado, a narradora permaneceu sentada).

A história contada por Dona Nair também pode ser qualificada como narrativa pessoal, no sentido aplicado por Ochs e Capps (2001), pois além de relatar uma experiência particular da contadora, possui aquelas características apontadas pelas autoras: tem um narrador ativo; seu relato é capaz de despertar interesse na audiência; é relativamente destacada do contexto de fala cotidiana (não é uma simples conversa); possui linearidade temporal e organização causal e tem uma argumentação moral definida.

No que tange à relação com a audiência, valem algumas observações especiais: a contadora, depois de assumir a responsabilidade pela narração, consegue combinar a seqüência cronológica dos fatos narrados com comentários e explicações sobre o contexto no qual estes ocorreram; esta preocupação em se fazer entender por esta audiência externa, no caso, a pesquisadora, e ao mesmo tempo obter a sua cumplicidade, faz com que a contadora recorra a expressões como "não é?" no final de algumas sentenças; influenciada talvez pelo que lhe diziam ser meu interesse nas "histórias dos antigos", Dona Nair, também faz questão de situar com detalhes o cenário material e moral - onde o evento se desenvolveu. Ingenuidade seria pensar que a narradora contou-me esta história da mesma forma como faria para membros de sua comunidade. Pelo contrário, até aquele momento a maior parte do pueblito onde ela vive desconhecia este trágico episódio de sua vida, por isto a surpresa de Verônica ao escutá-la. Problematizar esta questão, portanto, inspirada por Bertaux (1997), permite pensar no papel exercido pela pesquisa antropológica no estímulo e valorização da expressão da memória das pessoas "comuns" e de sua comunidade.

Este fragmento da história de vida de Dona Nair concentra alguns aspectos importantes da 'cultura da fronteira', dentre os quais saliento especialmente a questão do uso da violência física na resolução de conflitos e a experiência próxima, de grande parte da população, sobretudo a mais idosa, em eventos violentos. Outro aspecto que reforça a prática da violência na região é a menção, feita pela contadora, ao uso comum de armas de fogo - tanto no caso do pacto de morte do casal quanto do suicídio da garotinha em vista da provável morte da mãe, especificada abaixo. 
O desfecho deste "drama social", como pudemos acompanhar, se deu através da eliminação de um dos lados envolvidos (o casal apaixonado), deflagrando uma ruptura absoluta com a composição social anteriormente dada. O conflito, desta forma, operou uma transformação na vida de Dona Nair e de sua família, transformação que foi extensiva ao grupo do qual faziam parte. A seqüência do que podemos chamar de "assassinato consentido" e suicídio causou comoção à comunidade fronteiriça, tornando-se o mote de narrativas orais e escritas. Estas, por sua vez, salientam o "modelo de comportamento" contido no suicídio, explicitado nos últimos versos da décima: “(...) que dessa mesma morte eu perdi uma filha querida."

A contadora, durante a narrativa, ainda informa sobre outras práticas culturais da região (algumas em desuso atualmente), como a questão de "pagar a criação": era recorrente que famílias adotassem informalmente crianças, sobretudo filhos de empregados e, eventualmente, filhos bastardos do pai, e que estas posteriormente tivessem de prestar serviços à família que as acolheu. Ela também conta que, no período citado na história, os namoros se realizavam com a visita do jovem à casa da moça, sempre à tardinha (nunca pela manhã) e o jovem não deveria se aproximar demasiadamente da moça, nem falar-lhe em particular. Segundo Dona Nair, naquela época as mães eram muito cuidadosas com as filhas, sobretudo com as jovens moças (mas não as repreendiam em público), e havia uma clara divisão de tarefas entre os gêneros: os homens saíam para trabalhar (no campo, com os animais, ou na lavoura) e as mulheres permaneciam em casa cuidando dos filhos e realizando trabalhos domésticos.

No caso citado, a circulação de narrativas ganha especial relevância em se considerando que foi depois de ouvir a história da morte dos namorados que Dona Carolina, que morava em outro povoado da fronteira, escreveu a "décima". Mas esta só chegou aos ouvidos de Dona Nair porque foi publicada em um jornal uruguaio e graças à isso divulgada entre toda a população local, tanto de 'um lado' quanto de outro (Dona Nair à época vivia em São Gabriel/BR). Foi das páginas do jornal que a "décima" ganhou a oralidade, fazendo com que a história circulasse ainda mais pela região ${ }^{179}$. Outra informação ainda confirma a questão da convivência da população fronteiriça com a resolução violenta de conflitos: o verso final da "décima", "Que dessa mesma morte eu perdi uma filha querida" refere-se ao suicídio da filha de dez anos de Dona Carolina. Acreditando que a mãe, que estava muito doente, fosse morrer, a menina pegara a arma, do pai, que estava guardada embaixo de um travesseiro, e se matara.

Acredito que esta história de Dona Nair, intitulada mais tarde por outros membros da comunidade de "Romeu e Julieta dos Pampas", embora curta e descontextualizada de sua sequiência narrativa original, permite, por um lado, pela gama de informações que carrega, refletir sobre alguns dos principais

\footnotetext{
${ }^{178}$ Sobre a questão do alto índice de suicídios entre gaúchos da fronteira, ver o trabalho de Leal (1992).

${ }^{179}$ Vale ressaltar a mescla de idiomas que caracteriza esta 'cultura da fronteira', que ocorre, em grande parte, devido à esta circulação de narrativas orais e escritas ao longo de toda a região (Hartmann, 2005).
} 
elementos que compõem o caráter identitário da população fronteiriça. Por outro lado, pelo enfoque dado a sua forma de transmissão - sua performance possibilita o acesso às características narrativas de Dona Nair.

A importância de conhecer, registrar e analisar o contexto da narração e também da narrativa está relacionada à questão do significado: este passa a ser buscado não mais na própria história, mas no encadeamento particular das várias histórias e é relativo a um contexto específico de interação com a audiência. Neste sentido, a própria interpretação da audiência é estimulada pelo contexto (Kirshenblatt-Gimblett, 1975: 130). Finalmente, as contadoras em questão, demonstrando especial disposição, entusiasmo e, por que não dizer, generosidade, ao narrar, estão refletindo sobre sua própria experiência que, afinal, é também a experiência de viver numa fronteira, com sua cultura, seu imaginário, suas histórias e suas performances.

\section{Referências}

BAUMANN, Richard. Verbal Art as Performance. Rowley: Mass, Newbury House Publishers, 1977. Story, Performance and Event - Contextual Studies of Oral Narrative. Cambridge: Cambridge University Press, 1989.

BERTAUX, Daniel. Les Récits de Vie. Paris: Nathan, 1997.

DÉGH, Linda. Narratives in Society: a performer-centered study of narration. Helsinky: Academia Scientiarum Fennica: 1995.

HARTMANN, Luciana. Aqui nessa fronteira onde tu vê beira de linha tu vai ver cuento - tradições orais na fronteira entre Argentina, Brasil e Uruguai. Tese (Doutorado em Antropologia Social). Florianópolis: PPGAS/UFSC, 2004.

"Performance e experiência nas narrativas orais da fronteira entre Argentina, Brasil e Uruguai”. In: Revista Horizontes Antropológicos. PPGAS/UFRGS. n. 24, 2005.

JAKOBSON, Roman. "Linguística e Poética". In: Linguística e Comunicação. Tradução de Izidoro Bilkstein e José Paulo Paes. São Paulo: Cultrix, 1974.

KAPCHAN, Deborah A. "Common Ground: keywords for the study of expressive culture - Performance". In: Journal of American Folklore. v. 108, n. 430, 1995.

KIRSHENBLATT-GIMBLETT. "A Parable in Context : a social interactional analysis of storytelling performances". In: BEN-AMOS, Dan; GOLDSTEIN, Kenneth S. (orgs.) Folklore-Performance and Communication. Paris: Mouton, 1975.

LANGDON, Esther Jean.. "A Fixação da Narrativa: do Mito para a Poética da Literatura Oral”. In: Horizontes Antropológicos. Porto Alegre: PPGAS/UFRGS, ano 5, n. 12, 1999. LEAL, Ondina Fachel. "Honra, morte e masculinidade na cultura gaúcha". In: Brasil \& França: ensaios de Antropologia Social. Porto Alegre: Editora da UFRGS, 1992.

MAUSS, Marcel. “As Técnicas Corporais”. In:__. Sociologia e Antropologia. Vol. II. tradução de Mauro W. B. de Almeida. São Paulo: EPU, 1974.

OCHS, Elinor; CAPPS, Lisa. Living Narrative - Creating Lives in Everyday Storytelling. Cambridge/London: Harvard University Press, 2001.

SCHECHNER, Richard. Performance Theory. New York and London: Routledge, 1988. "Victor Turner's Last Adventure". In: TURNER, Victor. The Anthropology of Performance. 2a. ed. New York: P. A. J. Publications, 1992.

SCHIEFFELIN, Edward L. "On Failure and Performance: throwing the medium out of the séance". In: LEADERMAN, Carol; ROSEMAN, Marina (eds.) The Performance of Healing. London and New York: Routledge, 1996.

"Problematizing performance". In: HUGHES-FREELAND, Felicia (ed.) Ritual, Performance, Media. London and New York: Routledge, 1998. 
SINGER, Milton. When a Great Tradition Modernizes. Chicago: University of Chicago Press, 1972.

TURNER, Victor. Social Dramas and Stories about Them. In: MITCHELL, W. J. T. (org.) On Narrative. Chicago: University of Chicago Press, 1981.

The Anthropology of Performance. 2a. ed. New York: PAJ Publications, 1992.

ZUMTHOR, Paul. Performance, Recepção, Leitura. Tradução de Jerusa Pires Ferreira e Suely Fenerich. São Paulo: EDUC, 2000. 